\title{
EMBEDDED MODELLING AND SIMULATION SOFTWARE SYSTEM FOR ADAPTIVE ENGINEERING OF HYDRAULIC GEAR PUMPS
}

\author{
Opran Constantin Gheorghe ${ }^{\mathrm{a}}$, Ghionea Ionut ${ }^{\mathrm{a}}$, Pricop Mircea ${ }^{\mathrm{b}}$ \\ ${ }^{a}$ Politehnica University of Bucharest, 313 Splaiul Independenţei, 060042 Bucharest, Romania \\ ${ }^{b}$ HESPER SA, 1 Dr.Istrati Constantin, 040542 Bucharest, Romania
}

\begin{abstract}
The paper presents an analysis and validation method for a CAD model of a spur gear pumps series using FEM simulations. The analyzed pump is a new improved variant chosen among several constructive solutions created by parametric aided design in a range of gear pumps. Using mathematical computations and a calculus methodology there were identified the pressure values and forces generated in the pump assembly. The proposed study is especially applied to the gearing area and to the outlet chamber, where values and their variations are higher. FEM simulations are performed in these areas in order to identify and to present in a summary table the values of maximum stress, deformations and the percentages of calculation errors. The pump modelled and optimized by successive simulations led to the creation of an innovative gear pump series depending on the requirements imposed by the beneficiary.
\end{abstract}

Keyword: gear pumps; FEM analysis, CAD modelling; FEM simulation; adaptive engineering
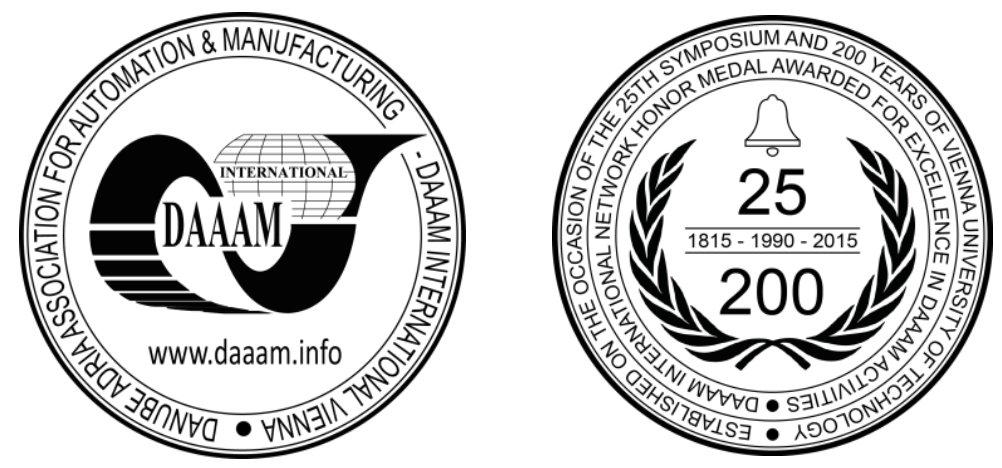

This Publication has to be referred as: Opran, C[onstantin]; Ghionea, I[onut] G[abriel] \& Pricop, M[ircea] (2016). Embedded Modelling and Simulation Software System for Adaptive Engineering of Hydraulic Gear Pumps, Proceedings of the 26th DAAAM International Symposium, pp.0311-0319, B. Katalinic (Ed.), Published by DAAAM International, ISBN 978-3-902734-07-5, ISSN 1726-9679, Vienna, Austria DOI:10.2507/26th.daaam.proceedings.042 


\section{Introduction}

The spur gear pumps are the most common types used with all pressure levels. Constructively, such a pump is composed of rotors mounted on the shaft or integral therewith, compensators, orientation pins, connectors, gaskets and assembling screws, a body and a cover. They are provided with holes that act as bearings for the shaft ends of the two gears. The complexity of the pump components is average, if we consider the pump as a final product, being determined by its functional role [1]. The volumes (the active cups) are composed of the gaps between the teeth that pass successively through the suction chamber and consequently create a suction pressure and form a surplus space as the teeth leave the meshing area. The gaps between the teeth are filled with fluid aspirated from the tank that is carried into the discharge chamber. Thus, the liquid is brought into the system under a certain hydrostatic pressure [2]. This type of pump operates under low pressure values (lubrication and cooling) ranging between 3 and 5 bar, under medium pressure values ranging between 25 and 150 bar, and under high pressures up to 350 bar. In addition, the pump flow rates are between 2 and $1000 \mathrm{l} / \mathrm{min}$, up to 30-40 kW power and velocities between 700 and $7000 \mathrm{rev} / \mathrm{min}$ [3]. The pump under consideration ensures a certain flow determined by the geometrical characteristics of the two toothed wheels of the gearing (number of teeth, module, width) and the driving velocity.

A properly chosen methodology of approach/parametric design, with the required steps of simulation and numerical computation may lead to the identification and validation of new design alternatives, with minimal effort and investments.

\section{Parametric design of pump assembly}

The modelling of the pump components was generally made on the basis of the shop drawings provided by the manufacturer [3], as well as the recommendations of the workshop production engineers. During the modelling process, one also resorted to a life-scale model. Some surfaces of the real life model required the additional measurements carried out in the "Dimensional Control Laboratory" of the Production Engineering Department-POLITEHNICA University of Bucharest. We have identified some possibilities for improving the shape of certain components, the identified dimensions being stored in order to create 3D models. Before proposing a modified pump prototype, its whole train, wholly patterned on a 3D model, was subjected to numerous simulation iterations by using finite elements. A milestone in the pump parametric modelling is to create a proper tooth profile shape, based on involute equations and sidewall line. Thus, one has obtained the gearing of the two toothed wheels, according to the conditions of the flow to be transmitted, the distance between the shaft axes and the dimensions of the seating assembly in the pump body. The pump gear is designed with corrected teeth, according to SR ISO 53: 2011 SR ISO 701: 2011 and ISO SR 677: 2011 [4]. The parameter equations (1) of the tooth profile (involute) are written as [5]:

$$
\left\{\begin{array}{l}
y d=r b \cdot(\sin (t \cdot \pi)-\cos (t \cdot \pi) \cdot t \cdot \pi) \\
z d=r b \cdot(\cos (t \cdot \pi)+\sin (t \cdot \pi) \cdot t \cdot \pi)
\end{array}\right.
$$

The involute curve, accordingly plotted, ends on the base circle of radius $r b=r p \times \cos (a l f a)=r p \times \cos (20) \approx$ $r p \times 0,94$. For a small number of teeth (to be found in pump gears), the radius $r f$ of the leg circle is smaller than the radius of the base circle. The next step in the design of the pump train is the modelling of the other components according to the specified dimensions. Throughout the modelling, one focused on the identification of the parameters included in the given formulas for parametric design. Thus, the parameters that have been taken into consideration were: the diameters of the bores supporting the wheel shafts, the diameters of the bores where the wheels are seated, mounted and turn, the distance between the axes of these bores, the depth of the seats wherein a workpiece is mounted, whose role is also functionally important, called compensator and the wheels (drive pinion and driven pinion) [5], [6]. Inside the pump body one mounts the parameterized design compensator so that the nominal diameters of its end profiles are equal to the diameter of the circle of head gears and implicitly, with the bore diameters inside the body. Also, the diameters of the penetrated bores are equal to the diameters of the wheel shafts, and the distance between the axes of these bores is equal to the distance between the shaft axes. The radii of the lateral recesses have been parameterized with discrete values, so that the hydraulic agent might reach the bores provided for ensuring the lubrication of the gear shaft bearings present in the pump body and cover [7]. Lubrication channels have been provided on the compensator front faces (the one that is in contact with the wheel front surface). A groove for the seal has been provided on the other surface. The dimensions of the sealing channel are parameterized with discrete values in order to comply with the typological-dimensional diversity of the seals used by the manufacturing company. In the wake of modelling, one acquires the 3D solid body of the pump, isometrically represented in Fig. 1. 


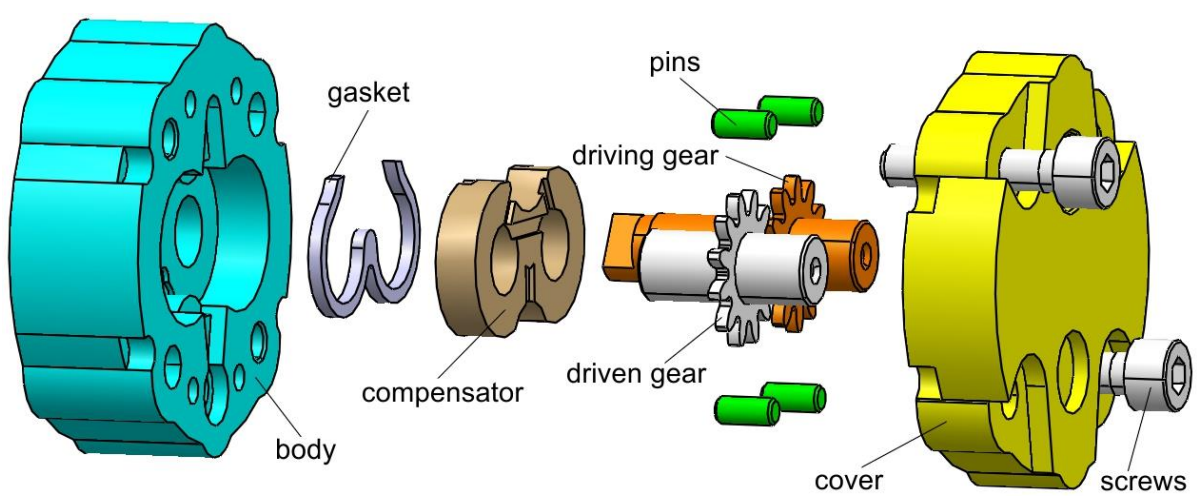

Fig. 1. The 3D isometric representation pump [3]

The modelled pump is part of a series of $\mathrm{H} 1$ pumps, with different dimensions and flow rates [3]. The model shown in Fig. 1 is the first in the series, featuring the lowest flow. In order to develop the other pumps in the series, one has to apply variations, via specific parameterization [5] [8] in CATIA V5, to certain dimensions, according to the functional and structural conditions imposed to the assembly under analysis. Once the geometric modelling has been completed, one further continues the pump parameterization in certain circumstances, namely, one considers the parameter of the pump flow that may be transmitted and directly related to one of the basic features of hydrostatic pumps, called geometric volume, expressed with relationship (2) [2], [9]

$$
V_{g}=2 \cdot z \cdot b \cdot A \cdot 10^{-3},\left[\mathrm{~cm}^{3} / \mathrm{rot}\right]
$$

where: $z$ - the number of teeth on each gear, $b$ - width of wheel, in mm, $A$ - area of the gap profile between two successive teeth, in $\mathrm{cm}^{2}$. The value of the geometrical volume is dependent on the specific parameters of the toothed wheels: module, number of teeth, angle head, correction coefficient and it decreases with an increasing number of teeth, which enlarges the inside pump gauge. The pump rate is calculated with relation (3):

$Q_{p}=\frac{V_{g} \cdot n}{10^{3}} \cdot \eta_{v},[1 / \mathrm{min}]$

where: $V_{g}$ - pump geometric volume in $\mathrm{cm}^{3} / \mathrm{rev}, n$-drive shaft velocity in rev / min while $\eta_{\mathrm{v}}$ - volumetric efficiency in $\%$. In the case under consideration, $n=1500 \mathrm{rev} / \mathrm{min}$, rated speed (minimum speed $\min n_{\min }=700 \mathrm{rev} /$ min and maximum speed $n_{\min }=6000 \mathrm{rev} / \mathrm{min}$ ) according to manufacturer's specifications and $\eta_{\mathrm{v}}=93 \%$ [3], [10] . Our aim has been to increase the geometric volume without changing the size and external shape of the semi-product used for manufacturing the pump body and cover, as they they are obtained by rolling. Thus, that would yield an increase of the flow to be handled by the pump, without making it necessary to choose the next pump in the series [3], [5], which differs in the size of its components. In addressing parametric design, one targets attaining the flow-rate values imposed by the manufacturer by considering a of standard type of pump, a certain design variant, a series of geometrical volumes, tooth geometry (module, number of teeth, angle head, correction parameters, width of teeth) and a nominal velocity. Based on a complex work methodology, detailed in [5], one calculates the parameters that define the width of the teeth, the width of the pump body, the depth bores (for wheels and clearing) made in the body and the compensator width, so that one obtains geometrical volumes featuring values $V_{g}=0,81 ; 0,99 ; 1,2 ; 1,7 ; 2,19 ; 2,62 ; 3,18 ; 3,54 ; 4,25$; $\mathrm{cm}^{3} / \mathrm{rev}$, corresponing to flow-rates $Q_{p}=2 ; 2,53 ; 3,18 ; 4,58 ; 6,05 ; 7,3 ; 8,98 ; 10,08 ; 12,23 ; 1 / \mathrm{min}$. The parameterized geometric models of the body, wheels and compensator are automatically remodelled based on the relationships and written reaction in Visual Basic, activated by the modification of the flow-rate values supplied by the pump flow [5], [11]. When a certain condition is met, the section succeeding it calculates the pump parameters and changes the 3D models of the pump components.

\section{Numerical determination of spur gear loading}

In order to study the behavior of the pump components under operating conditions, one has performed a simulation by using the finite element analysis. One has determined the loads (forces and pressures) that the pump assembly undergoes by using a certain calculation methodology [5], [12]. Thus, the bearings are loaded with the radial components of the elementary pressure forces on the wheels and the driving forces corresponding to the components of the pressure forces on the gear tooth flanks in each gap between two teeth. Across the arch of the head of each tooth, there emerges a pressure distribution, its variation between the gap zone and the head angle is considered to be very 
small, so that the pressure radial distribution (Fig. 2) is considered continuous. The drive forces, oriented along the line of contact $\Delta$ decompose tangentially and radially [13], [14].

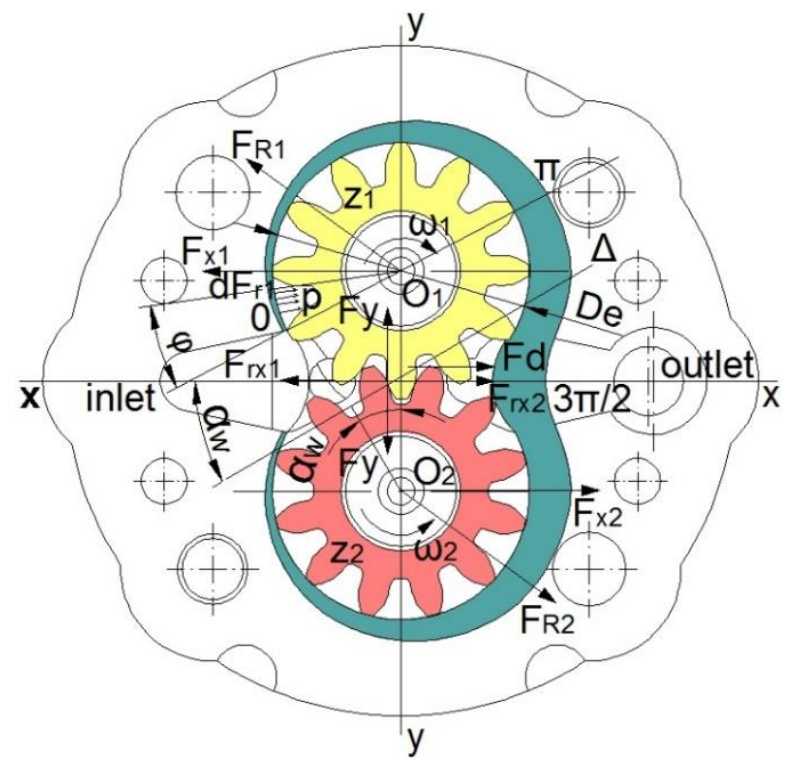

Fig. 2. Radial pressure distribution and application of forces acting on the gearing

It was found that with operation at the rated pump pressure, the pressure distribution is parabolical in shape [9], [15]. Taking into consideration the movement directions, with the angular velocities $\omega_{1}=\omega_{2}$ of the two wheels, the contact between any drive gear tooth and the engaged tooth of the driven wheel takes place at a point of the line of contact $\Delta$. Starting from this moment, the meshing teeth cause the liquid discharge in the gap between the teeth in the pump discharge zone. Similarly, there occurs the liquid pressure discharge in the other gaps as well, the rotations being continuous. The exertion of the pressures created on the peripheral surfaces of the wheels creates a strong moment of resistance which is overcome by engaging the driving wheel [3], [5]. The force that is applied to the teeth and the fluid in the direction $x-x$, as a result of torque applied to the driving wheel $\left(z_{1}\right)$ is calculated using relationship (4):

$F_{d}=\frac{2 \cdot M_{a}}{D_{w}},[\mathrm{~N}]$

where $M_{a}$ is the torque required by the drive shaft $(\mathrm{N} \cdot \mathrm{mm})$, while $D_{w}$ - rolling wheel diameter (mm). Moment $M_{a}$ results, with some approximations [9], from relationship (5):

$$
M_{a}=p \cdot m^{2} \cdot b \cdot\left(z_{1}+1\right),[\mathrm{N} \cdot \mathrm{mm}]
$$

where $p$ is the pressure created in the pump (the discharge chamber) during operation (bar), $b=\lambda \cdot m$ - the width of gear teeth $(\mathrm{mm}), \lambda$ - width ratio, $m$-gear teeth module $(\mathrm{mm})$, and $z_{1}$ - number of drive gear teeth. Let us consider the calculation formula (6) of the force applied to the toothing:

$$
F_{d}=2 \cdot p \cdot m \cdot b,[\mathrm{~N}]
$$

and represents the tangential component of the force acting on the drive gear teeth $z_{1}$. The fluid under pressure, to be found in the clearance between teeth, exerts pressure along the radial direction (Fig. 2) on both wheels, at a pressure ranging from a minimum value (atmospheric pressure in suction chamber) to the pressure in the discharge chamber considered as the pump nominal pressure. Across an angular variation, $\varphi \in(0 \ldots \pi)$, the pressure is on an upturn, while for $\varphi \in(\pi \ldots 3 \pi / 2)$, the pressure is considered [1] constant. At point $P$ of wheel circumference $z_{1}$, considered over interval $\varphi \in(0 \ldots \pi)$, the pressure created in the fluid transported to the discharge chamber is $p_{g z 1}=p \cdot \varphi / \pi$. This pressure creates an elemental radial force $d F_{r l}$ that acts on the wheel external circle chord $z_{1}$, corresponding to angle $d \varphi$. Thus, the respective force [2] is determined by relation (7):

$$
d F_{r 1}=p \cdot \frac{\varphi}{\pi} \cdot b \cdot \frac{D_{e}}{2} \cdot d \varphi,[\mathrm{N}]
$$


The elementary radial force acting over interval/range $\varphi \in(\pi \ldots 3 \pi / 2)$

$d F_{r 2}=p \cdot b \cdot \frac{D_{e}}{2} \cdot d \varphi,[\mathrm{N}]$

Based on these considerations, the total radial force $F_{r x}$ acting in the direction $x-x$ upon the gear is calculated with relation (9):

$F_{r x 12}=p \cdot b \cdot \frac{D_{e}}{2 \pi} \int_{0}^{\pi} \varphi \cdot \cos \varphi d \varphi+p \cdot b \cdot \frac{D_{e}}{2} \int_{\pi}^{\frac{3}{2} \pi} \varphi \cdot \cos \varphi d \varphi \approx 0,81 \cdot p \cdot D_{e 12} \cdot b,[\mathrm{~N}]$

where $\varphi$ - the turning angle of drive gear $z_{1}$, while $D_{e 12}$ - the outer wheel diameter, calculated with equation (10):

$D_{e 12}=m \cdot\left(z_{12}+2+2 \cdot \xi\right),[\mathrm{mm}] \quad,[\mathrm{N}]$

The engaging forces $F_{r x 1}, F_{r x 2}$ [2], [9] act in the same directions and in centers $O_{1}$, and and $O_{2}$, respectively, of the two wheels, wherein one considers that there are at work the resultant forces $F_{R 1}$ and $F_{R 2}$, respectively.

As shown in Fig. 2, the radial force [13] exerted on the wheel shaft $z_{1}$ in the direction $x-x$ is determined with relation (11):

$F_{x 1}=F_{r x 1}-F_{d}=\left(0,81 \cdot z_{1}-0,38+1,62 \cdot \xi\right) \cdot p \cdot m \cdot b,[\mathrm{~N}]$

and the force exerted on the driven wheel shaft $z_{2}$, in the same direction, with relationship (12):

$F_{x 2}=F_{r x 2}+F_{d}=\left(0,81 \cdot z_{2}+3,62+1,62 \cdot \xi\right) \cdot p \cdot m \cdot b,[\mathrm{~N}]$

The radial forces, calculated by using equation (13) and which act in the direction $y-y$ on the two meshing wheels shall be disregarded(according to radial pressure distribution

$$
F_{r y 12}=p \cdot b \cdot \frac{D_{e 12}}{2 \cdot \pi} \int_{0}^{\pi} \varphi \cdot \sin \varphi d \varphi+p \cdot b \cdot \frac{D_{e 12}}{2} \int_{\pi}^{\frac{3}{2} \pi} \sin \varphi d \varphi=0,[\mathrm{~N}]
$$

A radial (rejection) force is created, however, as a reaction to the meshing teeth, whose value is determined with relationship (14):

$$
F_{y}=F_{d} \cdot \operatorname{tg} \alpha_{w},[\mathrm{~N}]
$$

where the gearing angle $\alpha \mathrm{w}=230$, the gearing featuring displaced toothing [6].

The resultant forces FR1, and FR2, respectively, loading the drive and driven wheel bearings are determined with relations (15) and (16):

$$
\begin{aligned}
& F_{R 1}=p \cdot m \cdot b \cdot \sqrt{0,66 \cdot z_{1}^{2}+0,7 \cdot z_{1}+0,7},[\mathrm{~N}] \\
& F_{R 2}=p \cdot m \cdot b \cdot \sqrt{0,66 \cdot z_{2}^{2}+3,94 \cdot z_{2}+6,42},[\mathrm{~N}]
\end{aligned}
$$

For the calculation of the forces based on the above relationships, one considers the following values: $p=250$ bar, $m=2$ $\mathrm{mm}$ and $\xi=0,5 \mathrm{~mm}$, one calculates the values of forces $F_{d}, F_{r x 1}, F_{r x 2}, F_{x 1}, F_{x 2}, F_{y}, F_{R 1}$ and $F_{R 2}$ (Table 1).

\begin{tabular}{lllllllllll}
\hline \multirow{2}{*}{ No. } & $\begin{array}{l}V_{g}, \\
\mathrm{~cm}^{3}\end{array}$ & $\begin{array}{l}b, \\
\mathrm{~mm}\end{array}$ & $\begin{array}{l}P, \\
\mathrm{~kW}\end{array}$ & $\begin{array}{l}M_{a}, \\
\mathrm{~N} \cdot \mathrm{mm}\end{array}$ & $\begin{array}{l}F_{d}, \\
\mathrm{~N}\end{array}$ & $\begin{array}{l}F_{r x}, \\
\mathrm{~N}\end{array}$ & $\begin{array}{l}F_{x l}, \\
\mathrm{~N}\end{array}$ & $\begin{array}{l}F_{x 2}, \\
\mathrm{~N}\end{array}$ & $\begin{array}{l}F_{y}, \\
\mathrm{~N}\end{array}$ \\
\hline 1 & 0,81 & 2,3 & 0,59 & 2990 & 230 & 1397,25 & 1167,25 & 1627,25 & 96,6 & 1173 \\
\hline 2 & 0,99 & 2,8 & 0,74 & 3640 & 280 & 1701 & 1421 & 1981 & 117,6 & 1428 \\
\hline
\end{tabular}




\begin{tabular}{llllllllllll}
\hline 3 & 1,2 & 3,4 & 0,93 & 4420 & 340 & 2065,5 & 1725,5 & 2405,5 & 142,8 & 1734 & 2074 \\
\hline 4 & 1,7 & 4,8 & 1,35 & 6240 & 480 & 2916 & 2436 & 3396 & 201,6 & 2448 & 2928 \\
\hline 5 & 2,19 & 6,2 & 1,78 & 8060 & 620 & 3766,5 & 3146,5 & 4386,5 & 260,4 & 3162 & 3782 \\
\hline 6 & 2,62 & 7,4 & 2,15 & 9620 & 740 & 4495,5 & 3755,5 & 5235,5 & 310,8 & 3774 & 4514 \\
\hline 7 & 3,18 & 9 & 2,64 & 11700 & 900 & 5467,5 & 4567,5 & 6367,5 & 378 & 4590 & 5490 \\
\hline 8 & 3,54 & 10 & 2,97 & 13000 & 1000 & 6075 & 5075 & 7075 & 420 & 5100 & 6100 \\
\hline 9 & 4,25 & 12 & 3,60 & 15600 & 1200 & 7290 & 6090 & 8490 & 504 & 6120 & 7320 \\
\hline
\end{tabular}

Table. 1. Calculated values of forces acting on pump gearing and shafts

\section{Finite element simulation of spur gear loading}

By using the values of the forces and the pressure distribution, one has developed the FEM simulation model in order to validate the different variants of the parameterized design of the pump as a final product. By using the CATIA V5 program [16] one has undertaken simulations regarding the stress and strain distribution arising as a whole [17]. In fully secure conditions for the operation of the pump assembly, it is necessary that the effective loading taken into consideration in the calculation should be below the critical ones, determined by the allowable resistance of the material used in the parts under load. Depending on the permissible resistance value, one aims at preserving the deformations, in the elastic range, with a convenient safety factor [5], [14]. For the cover, body and compensator AlSi9Cu3 one has chosen an aluminum alloy $\mathrm{AlSi} 9 \mathrm{Cu} 3(\mathrm{Fe})$ featuring strength $R_{m}=2,6 \times 10^{8} \mathrm{~N} / \mathrm{m}^{2}$, for the wheels and their shafts one has chosen alloy steel with $R_{m}=3,5 \times 10^{8} \mathrm{~N} / \mathrm{m}^{2}$, while for fasteners (screws and pins) one has chosen carbon steel with $R_{m}=2,2 \times 10^{8} \mathrm{~N} / \mathrm{m}^{2} . \mathrm{Rm}=2,2 \times 10^{8} \mathrm{~N} / \mathrm{m} 2$. The pump discretization is achieved by defining a network of nodes and elements (mesh) of high precision for the meshing gears (size $=0,5 \mathrm{~mm}, 0,2 \mathrm{~mm}$ sag = parabolical) because they are the most loaded. [17]. The FEM analysis takes into account the other components acting as bearings in the wheel shafts: cover, body, compensator ( $\operatorname{size}=1,5 \mathrm{~mm} \mathrm{sag}=1 \mathrm{~mm}$, Linear Type). [12]. Applying virtual testing (force and pressure) on certain areas belonging to pump components will simulate the actual loading conditions to which the whole gear train is subjected during operation. For the whole assembly under analysis there have been applied tests of the distributed pressure and force loading type [3]. Inside the pump there are forces at work upon the toothing, radially distributed pressure into the gaps between the teeth and pressures in the bearings, on the flat surfaces of the cover and the compensator, in contact with the frontal surfaces of the wheels. The resultants of these loads determine the emergence of stresses and strain inside the pump [5], [10]. Pressures are applied to each wheel, in the gaps between teeth (Fig. 3), starting with a value of $1,5 \times 10^{6} \mathrm{~N} / \mathrm{m}^{2}$ to a value of $2,5 \times 10^{7} \mathrm{~N} / \mathrm{m}^{2}$ (250 bar), nominal operating pressure of the pump. The pressure applied increases in the radial distribution, the lowest value being in the suction chamber (inlet chamber), and the highest in the discharge chamber (outlet chamber) [5].

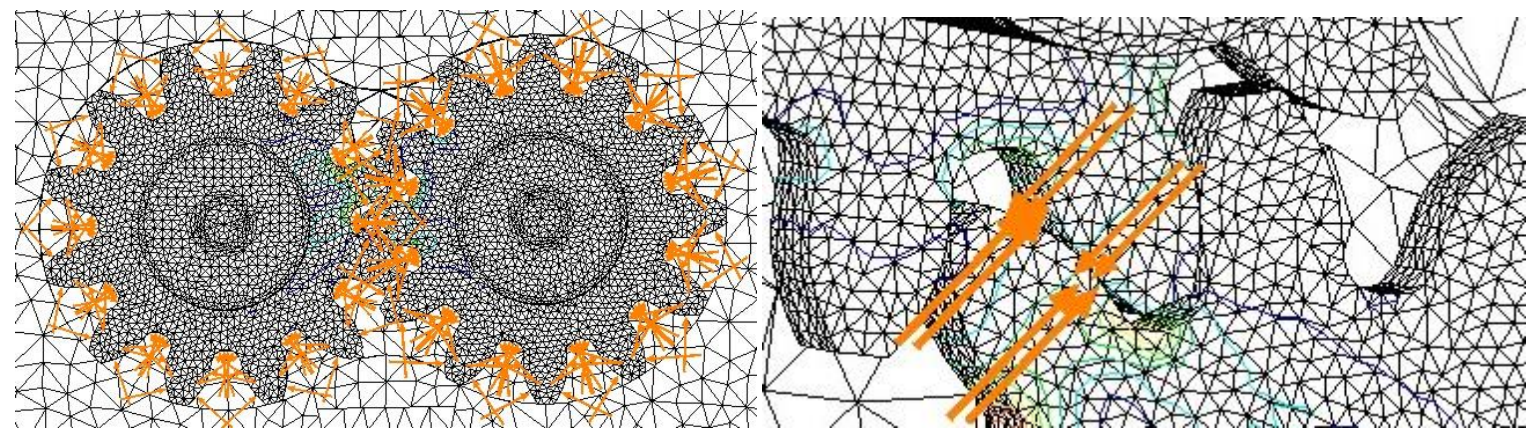

Fig. 3. Radial pressure distribution in the gaps between teeth and forces on teeth flanks

According to Figure 3, the meshing teeth are under the tangential action of two forces equal in value and of opposite sense, $F_{d}$, which, together with the forces generated by the pressure applied $\left(F_{\mathrm{rx} 1}\right.$ și $\left.\mathrm{F}_{\mathrm{rx} 2}\right)$, give rise to resultant forces $F_{x 1}, F_{x 2}$ in the meshing teeth and the wheel shafts. By combining these forces with the repulsion force emerging as a reaction of the meshing teeth, $F_{y}$, one obtains the resultant forces $F_{R 1}$ and $F_{R 2}$ that place a load on the driving and driven wheel bearings. Pressures and forces, thus distributed, lead to the stress loading of the toothing in the wheel crown and their shafts, as well as in the compensator, body and cover. The analysis of these components shows that the teeth are most under load when they reach the area where maximum pressure is exerted on the flanks, but also in the meshing area [10]. Based on the values given, one found out the existence of some deformations of the flanks, the values being obtained by FEM analysis. After performing specific calculations, we can determine, by simulation, maximum and minimum stresses arising in the main components of the pump, the strain and error coefficient of these calculations [17] for all the 9 variants parameterized according to Table 2. Peak loads occur with the latest version of 
the parameterized modelled (width of the teeth $b=12 \mathrm{~mm}$, tangential forces $F_{d}=1200 \mathrm{~N}$ ), The components most und $r$ load are naturally the wheel teeth, maximum stress $\left(2,84 \times 10^{8} \mathrm{~N} / \mathrm{m}^{2}\right)$ occurs in the follower wheel, and is located at the tooth foot [9].The driving wheel also features a maximum stress $\left(1,65 \times 10^{8} \mathrm{~N} / \mathrm{m}^{2}\right)$ located at the foot of the meshing gear teeth. Maximum stress values identified in the gear wheel models do not exceed the allowable resistance value $\left(3,5 \times 10^{8}\right.$ $\mathrm{N} / \mathrm{m}^{2}$ ) of the steel to be used in the manufacturing of the two components but they are on the verge of being accepted. Even if FEM simulation validates these three variants with an error rate of $\sim 7 \%$, it is necessary to test the prototype stage.

\begin{tabular}{|c|c|c|c|c|c|c|c|c|c|c|c|c|c|c|}
\hline \multirow[b]{2}{*}{ No. } & \multirow[b]{2}{*}{$\begin{array}{l}b, \\
\mathrm{~mm}\end{array}$} & \multirow[b]{2}{*}{$F_{d}, \mathrm{~N}$} & \multicolumn{3}{|c|}{ Driving gear } & \multicolumn{3}{|c|}{ Driven gear } & \multicolumn{2}{|c|}{ Compensator } & \multicolumn{2}{|l|}{ Body } & \multicolumn{2}{|l|}{ Cover } \\
\hline & & & $\begin{array}{l}\text { Stress, } \\
\times 10^{8} \\
\mathrm{~N} / \mathrm{m}^{2}\end{array}$ & $\begin{array}{l}\mathrm{D}, \\
\times 10^{-3} \\
\mathrm{~mm}\end{array}$ & $\begin{array}{l}\text { Er, } \\
\%\end{array}$ & $\begin{array}{l}\text { Stress, } \\
\times 10^{8} \\
\mathrm{~N} / \mathrm{m}^{2}\end{array}$ & $\begin{array}{l}\mathrm{D}, \\
\times 10^{-3} \\
\mathrm{~mm}\end{array}$ & $\begin{array}{l}\mathrm{Er} \\
\%\end{array}$ & $\begin{array}{l}\text { Stress, } \\
\times 10^{7} \\
\mathrm{~N} / \mathrm{m}^{2}\end{array}$ & $\begin{array}{l}\mathrm{Er} \\
\%\end{array}$ & $\begin{array}{l}\text { Stress, } \\
\times 10^{7} \\
\mathrm{~N} / \mathrm{m}^{2}\end{array}$ & $\begin{array}{l}\text { Er, } \\
\%\end{array}$ & $\begin{array}{l}\text { Stress, } \\
\times 10^{7} \\
\mathrm{~N} / \mathrm{m}^{2}\end{array}$ & $\begin{array}{l}\mathrm{Er} \\
\%\end{array}$ \\
\hline 1 & 2,3 & 230 & 1,52 & 4,8 & 5,41 & 1,96 & 7,4 & 3,28 & 1,44 & 12,2 & 3,12 & 11,3 & 2,3 & 10,2 \\
\hline 2 & 2,8 & 280 & 1,82 & 4,9 & 6,12 & 2,33 & 8,8 & 4,81 & 1,6 & 13,4 & 3,18 & 10,4 & 2,39 & 9,1 \\
\hline 3 & 3,4 & 340 & 1,54 & 5 & 4,98 & 2,41 & 8,9 & 4,98 & 1,37 & 16,2 & 3,23 & 11,1 & 2,42 & 8,93 \\
\hline 4 & 4,8 & 480 & 1,95 & 5,2 & 6,4 & 2,43 & 9,6 & 5,12 & 2,38 & 12,3 & 3,88 & 10,4 & 2,63 & 11,6 \\
\hline 5 & 6,2 & 620 & 1,64 & 5,4 & 6,1 & 2,39 & 10,1 & 6,2 & 2,33 & 11,4 & 3,75 & 9,3 & 2,91 & 9,6 \\
\hline 6 & 7,4 & 740 & 1,92 & 5,6 & 5,9 & 2,34 & 10,8 & 5,55 & 3,13 & 13,1 & 3,72 & 12,8 & 3,1 & 8,97 \\
\hline 7 & 9 & 900 & 2,12 & 6,1 & 5,87 & 2,32 & 11,3 & 6,25 & 2,97 & 11,4 & 4,65 & 11,5 & 3,32 & 10,2 \\
\hline 8 & 10 & 1000 & 1,63 & 6,38 & 6,54 & 2,56 & 11,7 & 6,87 & 4,25 & 13,9 & 4,29 & 11,1 & 3,82 & 9,1 \\
\hline 9 & 12 & 1200 & 1,65 & 6,65 & 7,08 & 2,84 & 12,7 & 5,78 & 4,17 & 14,5 & 4,21 & 13,2 & 4,43 & 8,56 \\
\hline
\end{tabular}

Table 2. Variation of maximum stresses, deformations and percentage error

The compensator features a maximum stress of $4,25 \times 10^{7} \mathrm{~N} / \mathrm{m}^{2}$, the body features $4,33 \times 10^{7} \mathrm{~N} / \mathrm{m}^{2}$ and the cover features $8,26 \times 10^{7} \mathrm{~N} / \mathrm{m}^{2}$. One remarks the more conspicuous stress distribution upon the driven wheel bearings (compensator and cover), in the meshing area and/or the maximum pressure zone created in the gaps of the teeth, as well as in the discharge area, upon the body and cap. Being aware of the FEM simulation range of practice and after analyzing all these tabulated results, one may assert that the parameterized variants of the model pump meet the imposed conditions and may go beyond the simulation stage [9]. Figure 4 shows the location of the maximum stress of the main pump components, for the third parameterized modelled variant. One may notice the areas with increasing stresses, as well as the pressure distribution between the teeth of the meshing wheels.
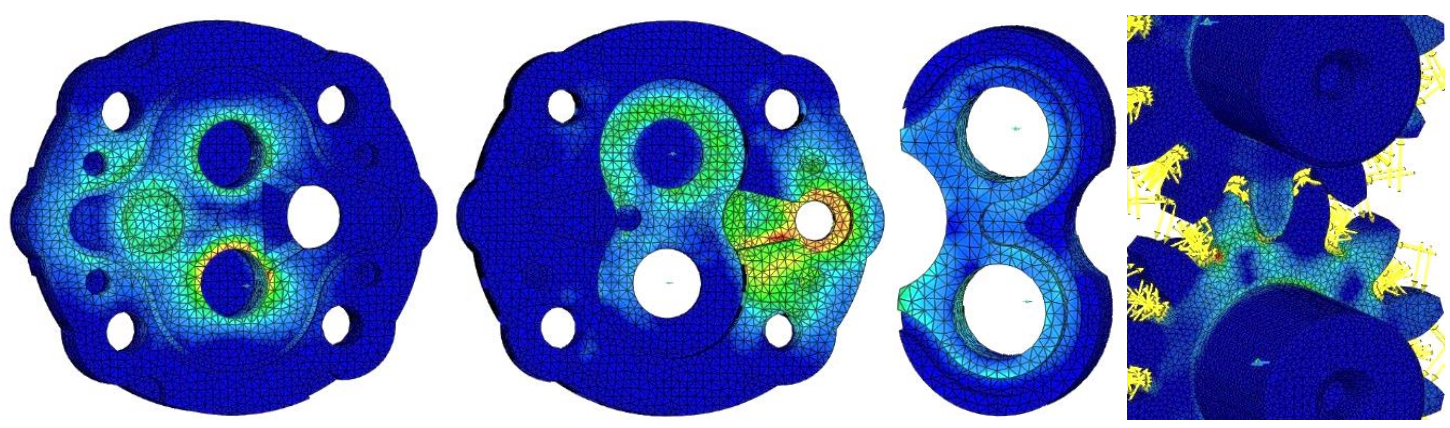

Fig. 4. Distribution of the main components of the pump tensions

The results obtained from the analysis show some error percentages, also tabulated. The error percentage occurs because it represents the difference between the models analyzed by FEM simulation of the pump components and its real pieces. In the industrial practice one considers that the model has been correctly refined if it features an error percentage of ranging between $5 \%$ and $15 \%$ [5], [17]. If the error is relatively high in a particular area of interest, there exists the possibility that the analytical results for the area might fail to be taken into consideration, the respective model should be refined and the calculation reiterated. In the wake of the FEM simulations conducted, one has found a distribution of high stresses in in the body and the cover, in the area of fluid discharge and orientation pins. If sudden pressure variations occur, these stresses may cause cracks and even rupture of parts in those respective areas, by the discharge area as well as pin and screw holes. Thus, in view of these problems, as well as other considerations, an improved version of a pump has been proposed (Fig. 5).The body of the new pump (parts located on the right) uses only 2 pins, not 4 like the previous solution (parts located on the left). Also, there was changed the position and diameter of the hole from the outlet chamber. The new pump cover has also only 2 pins, instead of 4 as was the case with in the previous pump. 


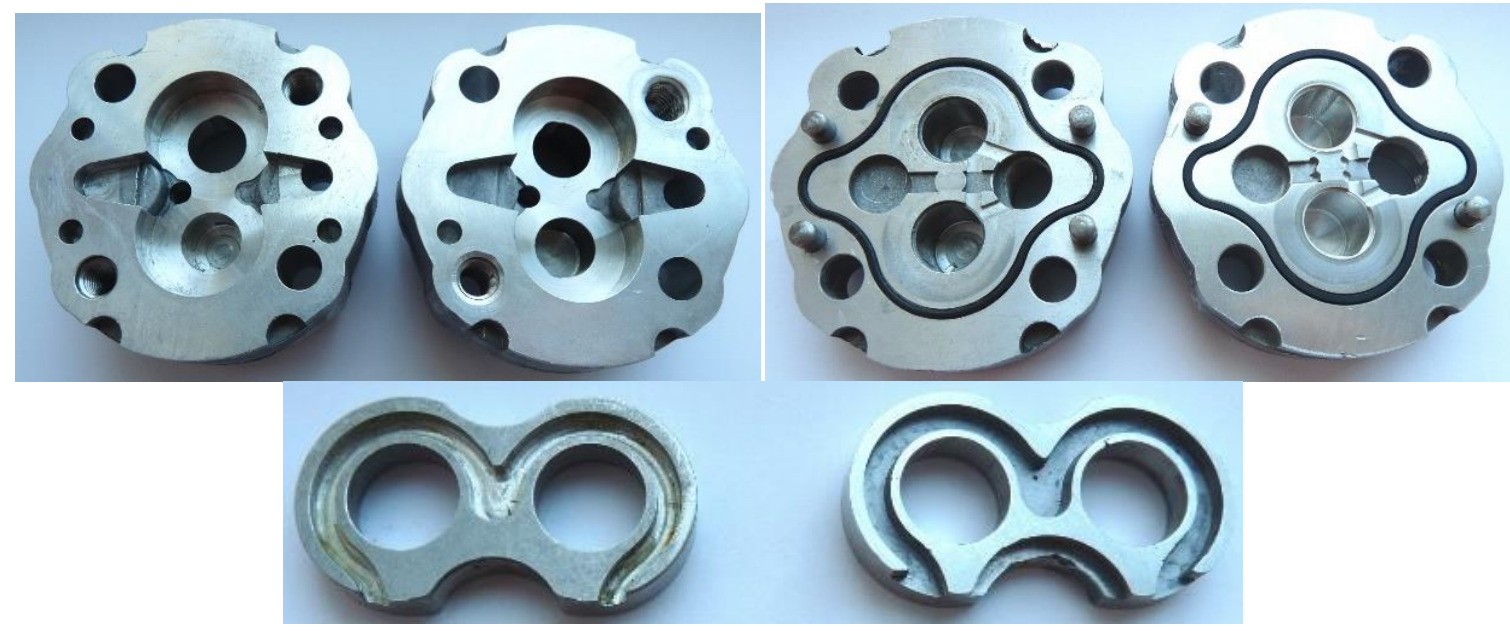

Fig. 5. Old and new versions of the pump body, cover and compensator

The new pump compensator has the gasket channel slightly larger and it is obtained directly from the casting phase. The previous compensator was contour milled. For the new compensator, a supplementary thin plastic gasket was added to better seal the pump chambers. It also prevents the movement and premature wear of the rubber gasket

\section{Conclusions}

The aim of the present research has been to ensure the engineering design optimization of spur gear pumps likely to yield high performance products. The basis of the research methodology was the use the FEM analysis of the maximum stresses in the components of spur gear pumps in simulation of the functioning conditions. This analysis made it possible to highlight the high stress areas arising during pump operation, more specifically in the pump body. The data thus obtained answered the initial research question concerning the relation between the level of stresses inside the pump body and the cylinder capacity. The resulted data showed that the higher the cylinder capacity is, the higher the stresses inside the pump body are.

By 3D parametric CAD modelling we created a simulation platform for a specific pump series, easy to modify, observe and improve. This means the initial conditions (calculation of forces, pressures, restraints etc.) have been are correctly identified and applied on the 3D model, which is enough refined to generate valid data for the whole pump series.

Limitations of the research is to not take into account the pressure pulsation and an increase of the hydraulic fluid temperature in the functioning time, which also has an impact on the effort of the pump components, limitation surpassed by using the highest values of loads available for this type of pumps.

The research results features a range of both applied and theoretical engineering issues. Thus:

a) Inside the pump body there have been highlighted dangerous areas of stress concentrations caused by high loading that resulted in life decrease under real functioning conditions;

b) The innovative compensator is not a radial bearing and is not dynamically loaded as it undergoes only compression loads;

c) The outcome of an optimum re-modelling has been that the pump assembly weight decreased from $587 \mathrm{~g}$ to $546 \mathrm{~g}$ while maintaining an imposed flow value and initial mechanical properties with implications for the efficiency of production and price reduction;

d) In the wake of research carried out on dangerous pump zones we have optimized the discharge zone from the pump body;

e The results of research performed on the parametric pump assembly provided the theoretical validation of all the 9 identified solutions, as the maximum stress values present in the components are lower than the yield strength of their materials.

Further research is to focus on a thermal analysis during the operation of the pump components and to pinpoint its implications upon the pump operation and reliability as well the verification of all prototype variants in experimental conditions by measuring the stress values, flows, noise and vibrations.

\section{Acknowledgement}

The work has been funded by project POSDRU/159/1.5/S/138963, Sectoral Operational Programme Human Resources Development 2007-2013 of the Ministry of European Funds and project 11DPST/2013, Double pumps with PHD Gr1 gears with innovative design, Contractor HESPER SA, the Executive Agency for Financing Higher Education, Research, Development and Innovation, PN II Program INNOVATION. 


\section{References}

[1] Radzevich, S., P., (2012), Dudley's Handbook of Practical Gear Design and Manufacture. CRC Press, Taylor\&Francis Group, LLC, ISBN 978-1-4398-6602-3, Boca Raton, USA.

[2] Vasiliu, N., Vasiliu, D., 2005, Hydraulic and pneumatic actuations Vol. I. Editura Tehnică, ISBN 973-31-2248-3, Bucharest, Romania.

[3] ***, Product Catalogue HESPER. Simple gear pumps.(2015); www.hesper.ro.

[4] ***, Standards on gears: SR ISO 53:2011, SR ISO 701:2011, SR ISO 677:2011.

[5] Ghionea, I., (2010), Researches on optimization by simulation of the industrial products design. Phd. Thesis, University Politehnica of Bucharest, Romania.

[6] Guowei, Li., Weijian, Mi., Kailiang, Lu., Weiguo Z., (2014), Reliability Analysis on Gear Contact Fatigue Strength. The Open Mechanical Engineering Journal, 8, pp. 630-635, ISSN 1874-155X, Bentham Science.

[7] Faggioni, M., Samani, F. S., Bertacchi, G., Pellicano, F. (2011), Dynamic optimization of spur gears. Mechanism and Machine Theory 46, pp. 544-557, ScienceDirect.

[8] Ghionea, I., (2013), Stude of computer aided design and simulation importance in the conception and development phases of a product. Proceedings of the IMC 2013 International Multidisciplinary Conference, North University of Baia Mare România - University College of Nyiregyhaza Hungary. pp.55-58. Bessenyei Publishing House, ISBN 978-615-5097-66-9.

[9] W. Kollek, U. Radziwanowska, (2014), Energetic efficiency of gear micropumps. Archives of Civil and Mechanical Engineering, Volume 15, Issue 1, January 2015, Elsevier, pp. 109-115, doi:10.1016/j.acme.2014.05.005.

[10] Chira, Flavia; Banica, Mihai; Lobontiu, Mircea; (2009); Optimising Involutes Asymmetrical Teeth Gears Software; Chapter 38 in DAAAM International Scientific Book 2009, pp. 363-376; B. Katalinic (Ed.), Published by DAAAM International, ISBN 978-3-901509-69-8, ISSN 1726-9687, Vienna, Austria.

[11] Raghunathan, C., Manoharan, C., (2014), Investigations of mechanical behavior in gear pump using design of software. International Journal of Engineering \& Technology, 3 (4), Science Publishing Corporation, pp. 435-444, doi: 10.14419/ijet.v3i4.1917.

[12] Jocanović, M., Šević, D., Karanović, V., Beker, I., Dudić, S., (2013), Increased Efficiency of Hydraulic Systems Through Reliability Theory and Monitoring of System Operating Parameters, Strojniški vestnik - Journal of Mechanical Engineering, 58, vol. 4, pp. 281-288, Croatia

[13] Opran C., Pricop M., Teodoru C.; (2015); Researches on Design and Manufacturing of Innovative Double Gears Pumps; 25th DAAAM International Symposium on Intelligent Manufacturing and Automation, DAAAM 2014; Procedia Engineering, 100 ( 2015 ) pp.475 - 481, Elsevier, 1877-7058.

[14] Pupăză, C., Kaloudis, A., Athanasiadis, G., (2006), Model for gear contact simulation, The 17th International DAAAM Symposium.Intelligent Manufacturing \& Automation: Focus on Mechatronics \& Robotics, ISBN 3-901509-57-7, Vienna, Austria.

[15] Mustata S. C., Dracea D., Tronac A. S., Sarbu N., Constantin E.; (2015) Diagnosis and Vibration Diminishing in Pump Operation; 25th DAAAM International Symposium on Intelligent Manufacturing and Automation, DAAAM 2014; Procedia Engineering, 100 ( 2015 ) pp.970-976, Elsevier, 1877-7058.

[16] ***, CATIA V5 documentation, (2015); Dassault Systemes.

[17] E. Mucchi, G. Dalpiaz, (2013), Experimental validation of a model for the dynamic analysis of gear pumps, in: 25th International Conference on Design Theory and Methodology, ASME, Portland, Oregon, USA. 